p-ISSN 1693-9484, $e$-ISSN : 2621-8313

Majalah Ilmiah Bahari Jogja (MIBJ)

Vol. 19 No. 2, Juli 2021

(35-42)

DOI: $10.33489 /$ mibj.v19i2.267

(C) 2021 Sekolah Tinggi Maritim Yogyakarta

\title{
Pengaruh Motivasi Dan Kontrak Psikologis Terhadap Kepuasan Kerja Serta Implikasinya Terhadap Kinerja Pegawai Politeknik Bumi Akpelni
}

Tini Utami $^{{ }^{*}}$, Suprihono Setyawan ${ }^{2}$, Evyana Diah Kusumawati ${ }^{3}$

1,3Politeknik Bumi Akpelni, Jl. Pawiyatan Luhur I / 1 , Bendan Dhuwur, Semarang

${ }^{2}$ Universitas Selamat Sri, Jalan Soekarno - Hatta, Km. 03, Kendal, Jawa Tengah

* Corresponding Author. e-mail : Utami.tini@yahoo.co.id. Telp : 08122532912

\begin{abstract}
Abstrak
Penelitian ini bertujuan untuk mengatahui pengaruh motivasi dan kontrak psikologis terhadap kepuasan kerja dan implikasinya terhadap kinerja pegawai Politeknik Bumi Akpelni Semarang. Penelitian ini adalah penelitian diskriptif kuantitatif dengan jumlah sampel 68 orang pegawai. Variabel dependen dalam penelitian ini kepuasan kerja dan kinerja sedangkan variabel independennya adalah motivasi dan kontrak psikologis. Dalam penelitian ini menggunakan metode purpose sampling sebagai teknik pengambilan sampel. Hasil penelitian menjelaskan bawah variabel kontrak psikolgis mempunyai hasil perhitungan $\mathrm{t}$ hitung $(0,538)$ dengan signifikansi $(0,000<0,05)$ sehingga disimpulkan bahwa variabel kontrak psikologis berpengaruh secara positisf dan signifikan, sedangkan variabel motivasi mempunyai hasil dengan perhitungan jalur path sebesar $(0,028)$ ini diartikan variabel motivasi juga dikatakan berpengaruh positif melalui kepuasan kerja. Dijelaskan dalam persamaan pertama bahwa adjusted $R^{2}$ square adalah 0,057 artinya 5,7\% dari variabel kepuasan kerja bisa dijelaskan oleh variasi kedua variabel bebas tersebut yaitu motivasi kerja dan kontrak psikologis, sedangkan 94,3\% dijelaskan oleh sebab yang lain diluar model penelitian ini, kemudian didalam persamaan kedua disebutkan bahwa adjusted $R^{2}$ square adalah 0,265 artinya $26,5 \%$ variabel kinerja bisa dijelaskan oleh variabel kontrak psikologis, sedang sisanya sebesar $73,5 \%$ dijelaskan oleh sebab yang lain diluar penelitian ini.
\end{abstract}

Kata Kunci: motivasi, kontrak psikologis, kepuasan kerja, kinerja

\begin{abstract}
The perpose of this study was to determine the effect of motivation and psychological contracts on job satisfaction and its implications for employee performance at the Bumi Akpelni Polytechnic Semarang. This study is a quantitative descriptive study with a sample of 68 employees. The dependent variable in this study is job satisfaction and performance, while the independent variables are motivation and psychological contract. In this study using the method of purpose sampling as a sampling technique. The results of the study explain that the psychological contract variable has a t-count calculation (0.538) with a significance $(0.000<0.05)$ so it can be concluded that the psychological contract variable has a positive and significant effect, while the motivation variable has a result with a path calculation of (0.028). it means that the motivation variable is also said to have a positive effect through job satisfaction. It is explained in the first equation that the adjusted $R 2$ square is 0.057 meaning
\end{abstract}


$5.7 \%$ of the job satisfaction variable can be explained by the variation of the two independent variables, namely work motivation and psychological contract, while $94.3 \%$ is explained by other reasons outside this research model. in the second equation it is stated that the adjusted $R 2$ square is 0.265 , meaning that $26.5 \%$ of the performance variable can be explained by the psychological contract variable, while the remaining $73.5 \%$ is explained by other reasons outside this study.

Keywords: motivation, psychological contract, job satisfaction, performance

\section{PENDAHULUAN}

Politeknik Bumi Akpelni (PBA) sebagai salah satu Perguruan Tinggi Swasta Maritim yang berada di Jawa Tengah yang merupakan perubahan bentuk dari Akademi Pelayaran Niaga Indonesia (AKPELNI) didirikan pada tanggal 17 September 1964. Diawal berdiri AKEPLNI mempunyai 3 (tiga) Jurusan yaitu Nautika, Teknika dan Ketatalaksanaan Pelayaran Niaga dan Kepelabuhan semuanya dalam jenjang program D3, dalam perkembangannya menjadi Politeknik Bumi Akpelni menambah satu program studi lagi yaitu Transpotasi Laut jenjang S1 (Sarjana Terapan), dan saat ini telah mendapatkan akreditasi dari BAN PT dengan predikat "B"

Politeknik Bumi Akpelni juga telah mendapatkan sertifikat pengesahan dari Direktur Jendral Perhubungan Laut Kementrian Perhubungan untuk penyelenggaraan Diklat Ahli Teknika Tingkat III, Ahli Nautika Tingkat III serta penyelenggaraan Diklat-diklat ketrampilan lainnya, seperti : BRM, ERM, Radar Simulator, Arpa Simulator, ECDIS Simulator, GMDSS Simulator, ORU, SAT, SDSD, SSO, MC dan MFA training program. Politeknik Bumi Akpelni menerapkan sistem manajemen mutu menggunakan standar ISO 9001:2015 tersertifikasi dari SAI Global Astralia No. QEC25694.

Sebagai salah satu lembaga pendidikan tinggi bidang maritim di Semarang maka manajemen Politeknik Bumi Akpelni harus senantiasa mempertahankan reputasi terssebut dengan memberikan peyanan prima kepada pengguna jasa khususnya pendidikan kemaritiman dan kepelabuhan serta traspotasi laut , sehingga hal ini perlu diketahui oleh para pegawai Politeknik Bumi Akpelni agar sikap dan perilaku mereka dalam melaksanakan tugas dan memberikan pelayanan betul-betul optimal. Dengan pemberian pelayanan dengan optimal akan menciptakan kepuasan pengguna jasa yang akan berkelanjutan pada loyalitas pengguna jasa tersebut dan akhirnya akan berimbas pada kinerja.

Akan tetapi, dalam kenyataannya masih terdapat pegawai yang mangkir, terkadang bolos, tanggungjawab terhadap pekerjaan masih belum maksimal karena disebabkan motivasi kerja terkadang kurang dan belum terpenuhinya kontrak psikologis dalam diri individu mereka sebagaimana contoh mereka memerlukan waktu untuk dapat diberi kesempatan dipromosikan, mutasi sehingga secara psikologis mengakibatkan kepuasan kerja berkurang dan menjadikan kinerjanya menurun (Sumber : Politeknik Bumi Akpelni 2019).

Dari paparan latar belakang yang telah diuraikan di atas bahwaterdapat masalah yang ada di Politeknik Bumi Akpelni terkait kurangnya motivasi kerja 
pegawai dan belum terpenuhinya kontrak psikologis dari individu pegawai sehingga hal ini mengakibatkan kepuasan kerja berkurang dan kinerjanya menurun. Dari penjelasan yang telah disampaikan diatas dapat dirumuskan permasalahan penelitian sebagai berikut: Bagaimana motivasi berpengaruh terhadap kepuasan kerja pegawai Politeknik Bumi Akpelni ?, bagaimana kontrak psikologis berpengaruh terhadap kepuasan kerja pegawai Politeknik Bumi Akpelni ?, bagaimana kepuasan kerja berpengaruh terhadap kinerja pegawai Politeknik Bumi Akpelni?

\section{KAJIAN LITERATUR}

\section{Motivasi Kerja}

Motivasi mempersoalkan bagaimana cara mengarahkan daya dan potensi agar bekerja mencapai tujuan yang ditentukan (Hasibuan, 2006).

Pada dasarnya motivasi bertitik tolak pada individu. Motivasi muncul ketika seorang individu mengalami kekurangan akan suatu kebutuhannya. Kekurangan kebutuhan itu bersifat fisiologi maupun bersifat psikologi. Kekurangan akan suatu kebutuhan inilah yang menjadi pembangkit, penguat atau penggerak perilaku. Proses motivasi seperti ini diinterpretasikan oleh sebagian ahli teori sebagai pengarahan kepada suatu tujuan (Arep Ishak and Tanjung Hendri, 2003). Ada 3 (tiga) cara yang dapat digunakan oleh seorang manajer untuk memotivasi bawahannya yaitu (1) beri pengakuan; (2) Buat pekerjaan mereka lebih menarik; dan (3) beri mereka tanggung jawab tambahan; (Winardi, 2002).

\section{Kontrak Psikologis}

Kontrak mengikat karyawan serta perusahaan dalam suatu persatuan kerja, mengatur perilaku masing-masing pihak dalam perusahaan serta memungkinkan pencapaian tujuan perusahaan (Anoraga Pandji, 2001)

Kontrak psikologis pertama kalinya dikenal oleh Argyris (dalam Ashar, 2001), untuk menjelaskan perihal hubungan antara perusahaan dengan karyawannya. Argyris berpendapat bahwa pemahaman sebuah kontrak psikologis akan berkembang diantara perusahaan dan karyawan jika perusahaan menghormati norma-norma budaya informal karyawan : mengembangkan karier (career devolopment), Kebebasan dalam bekerja (job contents), suasana dan kondisi kerja (social atmosphere), kepedulian perusahaan atas kesejahteraan pribadi karyawan (work-life balance). Kontrak psikologis walaupun bukan merupakan kontrak resmi namun demikian hal tersebut nyata ada didalam pikiran karyawan dan perusahaan. Hal ini merupakan perluasan atas konsep kontrak kerja formal yang tertulis, terucap dan terobservasi. Kontrak psikologis merupakan salah satu kekuatan sikap dan perilaku kerja karyawan (Ashar, 2001).

\section{Kepuasan Kerja}

Kepuasan kerja menurut (Robbins. P.S, 2002) kepuasan kerja adalah "sikap umum terhadap pekerjaan seseorang yang menunjukkan perbedaan antara jumlah penghargaan yng diterima pekerja dan jumlah yang mereka yakini seharusnyamereka terima”. Robbins melihat kepuasan kerja seorang 
karyawan/individu berdasarkan besar kecilnya imbalan yang diterima oleh seorang karyawan.

Hariandja (2002) memandang kepuasan kerja tidak hanya sebatas besar kecilnya imbalan yang diterima oleh seorang karyawan tetapi lebih luas lagi yaitu persepsi individu dalam memandang sejauh mana dia merasa secara positif maupun negatif atas berbagai atau dimensi-dimensi dari tugas pekerjaannya.

\section{Kinerja Pegawai}

Kinerja merupakan seperangkat hasil yang ingin dicapai yang merujuk pada tindakan pencapaian serta pelaksanaan suatu pekerjaan yang diminta. Kinerja merujuk pada pencapaian karyawan atas tugas yang diberikan (Furtwengler, 2000). Untuk mengetahui prestasi kerja karyawan perlu adanya penilaian. Sistem penilaian harus mempunyai hubungan dengan pekerjaan (job related), praktis, mempunyai standar-standar dan menggunakan berbagai ukuran yang dapat diandalkan. Adapun teknik-teknik yang digunakan oleh pihak manajemen dalam menilai prestasi kerja karyawan dapat berupa : rating scale, checklist, metode peristiwa kritis, filed reviewmethod, tes dan observasi prestasi, dan metode evaluasi kelompok (Furtwengler, 2000).

\section{Pengembangan Model}

Bertitik tolak dari uraian dalam pendahuluan dan landasan teori tersebut diatas, maka desaian modelnya adalah sebagi berikut :

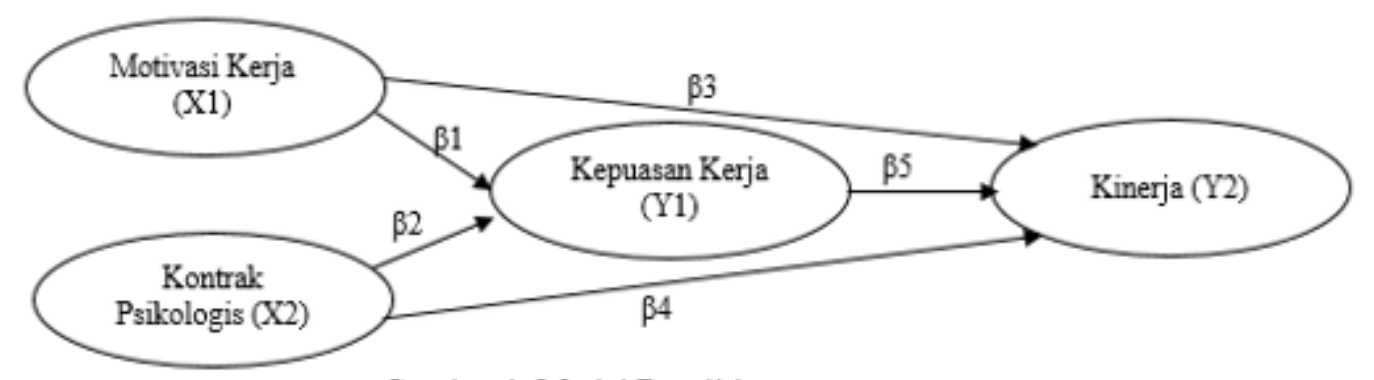

Gambar 1. Model Penelitian

\section{Hipotesis Penelitian}

Dari pengembangan diatas dapat dijelaskan tentang hipotesis penelitiannya sebagai berikut :

H1 : diduga variabel motivasi kerja mempunyai pengaruh positif dan signifikan terhadap kinerja melalui kepuasan kerja.

H2 : diduga variabel kontrak psikologis mempunyai pengaruh positif dan signifikan dari terhadap kinerja melalui kepuasan kerja.

\section{Definisi Operasional Variabel}

Dalam penelitian ini yang menjadi variabel bebas adalah motivasi kerja dan kontrak psikologis sedangkan yang menjadi terikat adalah kepuasan kerja dan kinerja, kemudian sebagai indikator dari tiap-tiap varaibel adalah sebagai berikut :

1. Variabel Motivasi kerja terdiri dari : prestasi, afiliasi, kekuasaan. 
2. Variabel Kontrak psikologis terdiri dari : pengembangan karier, kebebasan bekerja, suasana kerja, penghargaan financial, penghargaan non finacial dan kepedulian instansi atas kesejahteraan pegawai.

3. Variabel Kepuasan kerja terdiri dari : pekerjaan itu sendiri, gaji, promosi, penyelia, rekan kerja.

4. Variabel Kinerja terdiri dari : produktifitas, kualitas, efektifitas.

\section{METODE PENELITIAN}

Dalam penelitian ini yang menjadi responden adalah semua pegawai di Politeknik Bumi Akpelni yang berjumlah 68 orang, yang terdiri dari pegawai lakilaki sejumlah 30 orang (44\%) dan pegawai perempuan sejumlah 38 orang (56\%). Sedangkan rentang usia dari responden adalah $25-40$ tahun sejumlah 14 orang (22\%), rentang usia $41-50$ tahun sejumlah 33 orang (48\%), rentang usia $51-60$ tahun sejumlah 10 orang (14\%) dan rentang usia diatas 61 tahun sejumlah 11 orang (16\%). Sehingga dapat dijelaskan bahwa responden dengan rentang usia 41 - 50 adalah jumlah terbanyak dalam penelitian ini. Kemudian dihitung dari masa kerja maka dapat dijelaskan sebagi berikut, masa kerja kurang dari 10 tahun terdapat 9 orang (13\%), masa kerja dengan rentang 10-15 tahun terdapat 20 orang (29\%), masa kerja dengan rentang 16-20 tahun terdapat 11 orang (17\%), masa kerja dengan rentang 21-30 tahun terdapat 20 orang (29\%) dan masa kerja dengan rentang lebih dari 30 tahun sejumlah 8 orang $(12 \%)$.

Penelitian ini kuisioner langsung dibagikan kepada pegawai Politeknik Bumi Akpelni, dengan masa tunggu pengembalian kuisoner selama 2 hari kerja, selama kurun waktu tersebut semua responden mengembalikan lembar kuisioner, ini artinya respon rate dalam penelitian ini mencapai angka sempurna yaitu $100 \%$. Olah data yang di support dengan software SPSS menggunakan analisis regresi linier(Astriawati, 2016).

\section{PEMBAHASAN}

Dari hasil olah data yang di support oleh software SPSS, maka dapat dijelaskan dalam Tabel 1 dibawah ini menjelaskan hasil analisis regresi linier, sebagai berikut :

Tabel 1. Hasil Regresi

\begin{tabular}{|c|c|c|c|c|}
\hline Model & Variabel Dependent & Variabel Independent & Koeffisien & Sig \\
\hline \multirow[t]{3}{*}{1} & Kepuasan Kerja (Y1) & $\begin{array}{l}\text { Motivasi Kerja (X1) } \\
\text { Kontrak Psikologis (X2) }\end{array}$ & $\begin{array}{l}0,212 \\
0,144\end{array}$ & $\begin{array}{l}0,094 \\
0,252\end{array}$ \\
\hline & Adjusted $R^{2}$ & $=0,057$ & & \\
\hline & $\mathrm{Uji}_{\mathrm{F}}$ & $=3,018$ & & \\
\hline \multirow[t]{3}{*}{2} & Kinerja (Y2) & $\begin{array}{l}\text { Motivasi Kerja (X1) } \\
\text { Kontrak Psikologis (X2) } \\
\text { Kepuasan Kerja (Y1) }\end{array}$ & $\begin{array}{r}-0,167 \\
0,538 \\
0,134 \\
\end{array}$ & $\begin{array}{l}0,144 \\
0,000 \\
0,227 \\
\end{array}$ \\
\hline & Adjusted $\mathrm{R}^{2}$ & $=0,265$ & & \\
\hline & $\mathrm{Uji}_{\mathrm{F}}$ & $=9,040$ & & \\
\hline
\end{tabular}

Sumber : data primer yang diolah 2021 
1. Dari tabel 1 tersebut diatas didapat persamaan regresi 1 sebagai berikut :

$$
\mathrm{Y}_{1}=0,212 \mathrm{X}_{1}+0,144 \mathrm{X}_{2}+\mathrm{e}_{1}
$$

persamaan 1 diatas menjelaskan bahwa semua variabel bebas mempunyai tanda positif, artinya apabila terjadi peningkatan variabel bebas yang mempunyai tanda positif, maka variabel terikat kepuasan kerja juga akan mengalami peningkatan.

2. Selanjutnya didapat persamaan regresi 2 dengan hasil sebagai berikut :

$$
\mathrm{Y}_{2}=-0,167 \mathrm{X}_{1}+0,538 \mathrm{X}_{2}+0,134 \mathrm{Y}_{1}+\mathrm{e}_{2}
$$

persamaan 2 diatas pada variabel motivasi kerja pertanda negatif, sedangkan pada variabel kontrak psikologis dan variabel kepuasan kerja bertanda positif, artinya apabila dua variabel bertanda positif tersebut mengalami peningkatan maka hal ini akan diikuti juga oleh variabel kinerja.

3. Tabel 1 di persamaan pertama diatas dijelaskan bahwa adjusted $R^{2}$ adalah 0,057 artinya $5,7 \%$ dari variabel kepuasan kerja bisa dijelaskan oleh variasi kedua variabel bebas tersebut yaitu motivasi kerja dan kontrak psikologis, sedangkan 94,3\% dijelaskan oleh sebab yang lain diluar model penelitian ini.

4. Sedangkan dalam tabel 1 persamaan kedua disebutkan bahwa adjusted $R^{2}$ adalah 0,265 artinya 26,5\% variabel kinerja bisa dijelaskan oleh variabel kontrak psikologis, sedang sisanya sebesar $73,5 \%$ dijelaskan oleh sebab yang lain diluar penelitian ini.

5. Dari hasil uji mediasi yang menggunakan metode analisis jalur (path analysis), dapat dijelaskan dibawah ini :

$\beta 1=0,212$ (koeffisien regresi motivasi kerja terhadap kepuasan kerja)

$\beta 2=0,144$ (koeffisien regresi kontrak psikologis terhadap kepuasan kerja)

$\beta 3=-0,167$ (koeffisien regresi motivasi terhadap kinerja)

$\beta 4=0,538$ (koeffisien regresi kontrak psikologis terhadap kinerja)

$\beta 5=0,134$ (koeffisien regresi kepuasan kerja terhadap kinerja)

selanjutnya model grafis didapat analisa jalur path yang nampak dalam gambar berikut ini :

a. Uji dari efek pengaruh motivasi kerja terhadal kinerja melalui kepuasan kerja

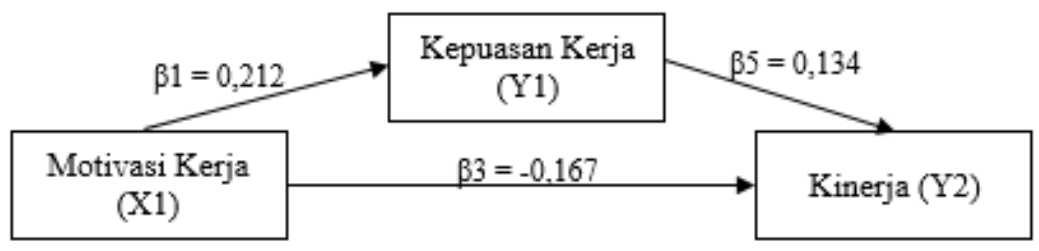

Gambar 2. Jalur Path 1

Hasil perhitungan jalur path 1 adalah sebagai berikut :

Jalur langsung

: $-0,167$

Jalur tidak langsung $(\beta 10,212 \times \beta 50,134) \quad: \quad 0,028$ 
dari hasil perbandingan pengaruh langsung dan pengaruh tidak langsung, maka dapat disimpulkan bahwan pengaruh tidak langsung lebih besar dari pengaruh langsung $(0,028>-0,167)$, maka dapat diartikan bahwa variabel kepuasan kerja bisa menjadi mediasi variabel motivasi kerja terhadap kinerja melalui kepuasan kerja

b. Uji dari efek pengaruh kontrak psikologis terhadap kinerja melalui kepuasan kerja

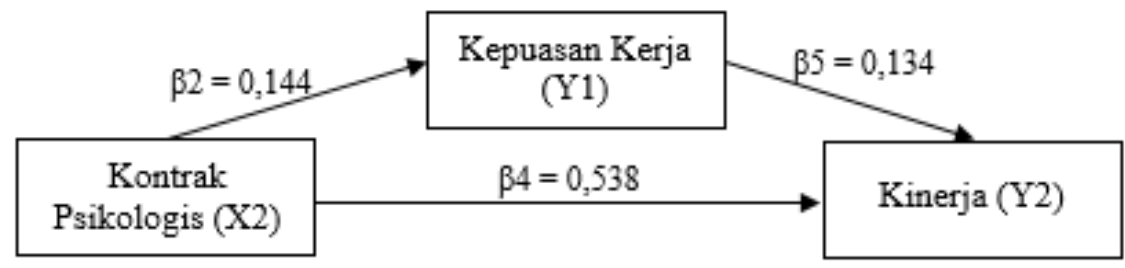

Gambar 3. Jalur Path 2

Hasil perhitungan jalur path 2 adalah sebagai berikut :

Jalur langsung $\quad: 0,538$

Jalur tidak langsung $(\beta 20,144 \times \beta 50,134) \quad: \quad 0,019$

dari hasil perbandingan pengaruh langsung dan pengaruh tidak langsung, maka dapat disimpulkan bahwan pengaruh tidak langsung lebih kecil dari pengaruh langsung $(0,538<0,019)$, maka dapat diartikan bahwa variabel kepuasan kerja tidak bisa menjadi mediasi variabel kontrak psikologis terhadap kinerja melalui kepuasan kerja.

c. Perbandingan jalur path 1 dan jalur path 2 dapat disimpulkan sebagai berikut :

1) Memperlihatkan bahwa variabel kontrak psikologis berpengaruh langsung terhadap variabel kinerja dengan nilai beta $=0,538$, dengan demikian kepuasan kerja tidak dapat menjadi mediasi bagi variabel kontrak psikologis terhadap kinerja.

2) Memperlihatkan bahwa variabel kepuasan kerja menjadi mediasi dari varaibel motivasi kerja terhadap kinerja dengan nilai beta $=0,028$.

6. Penelitian ini membuktikan bahwa variabel kontrak psikologis memberikan pengaruh positif dan signifikan terhadap kinerja di Politeknik Bumi Akpelni Semarang.

\section{PENUTUP}

\section{Kesimpulan}

Dapat dijelaskan bahwa dari penelitian bisa disimpulkan bahwa : Kinerja dapat ditingkatkan dengan kontrak psikologis, ini dapat dilihat dari adanya pengembangan karier, kebebasan bekerja, suasana kerja, penghargaan financial, penghargaan non finacial selain itu para pegawai berharap kepada pimpinan bawah perlu lebih ditingkatkan lagi kepedulian instansi atas kesejahteraan pegawai. Sedangkan faktor lain yang dapat meningkatkan kinerja adalah motivasi 
dengan tanggung jawab terhadap perkerjaannya dan pekerjaan itu sesuai dengan kompetensinya serta dukungan dari sesama rekan kerja.

\section{Saran}

Hasil dari penelitian ini membutktikan bahwa kinerja dipengaruhi oleh kontrak psikologis, oleh karenanya pimpinan Politeknik Bumi Akpelni harus bisa meningkatkan faktor kontrak psikologis, motivasi dan kepuasan kerja serta meningkatkan kepedulian terhadap kesejahteraan pegawai.

\section{DAFTAR PUSTAKA}

Anoraga Pandji. (2001). Psikologi Kerja. Asdi Mahasatya.

Arep Ishak and Tanjung Hendri. (2003). Manajemen Motivasi. PT. Gramedia Widiasarana Indonesia.

Ashar, S. M. (2001). Psikologi industri dan organisasi. Jakarta: Universitas Indonesia.

Astriawati, N. (2016). Penerapan Analisis Regresi Linier Berganda Untuk Menentukan Pengaruh Pelayanan Pendidikan Terhadap Efektifitas Belajar Taruna Di Akademi Maritim Yogyakarta. Majalah Ilmiah Bahari Jogja, 14(23), 22-37.

Furtwengler, D. (2000). Penilaian Kinerja. Andi.

Hariandja, M. T. E. (2002). Manajemen sumber daya manusia. Grasindo.

Hasibuan, M. S. . (2006). Organisasi dan Motivasi. PT. Bumi Aksara.

Robbins. P.S. (2002). Prinsip-prinsip perilaku organisasi. Edisi Kelima. Erlangga.

Winardi, J. (2002). Motivasi dan pemotivasian dalam manajemen. Jakarta: PT. Raja Grafindo Persada. 